San Jose State University

SJSU ScholarWorks

Master's Theses

Master's Theses and Graduate Research

1995

\title{
A pilot study describing neurologic assessment tools used by school nurses to determine at-risk learners in the grade school population
}

Carol Pette Bergner

San Jose State University

Follow this and additional works at: https://scholarworks.sjsu.edu/etd_theses

\section{Recommended Citation}

Bergner, Carol Pette, "A pilot study describing neurologic assessment tools used by school nurses to determine at-risk learners in the grade school population" (1995). Master's Theses. 1119.

DOI: https://doi.org/10.31979/etd.tbu7-k7yh

https://scholarworks.sjsu.edu/etd_theses/1119

This Thesis is brought to you for free and open access by the Master's Theses and Graduate Research at SJSU ScholarWorks. It has been accepted for inclusion in Master's Theses by an authorized administrator of SJSU ScholarWorks. For more information, please contact scholarworks@sjsu.edu. 


\section{INFORMATION TO USERS}

This manuscript has been reproduced from the microfilm master. UMI films the text directly from the original or copy submitted. Thus, some thesis and dissertation copies are in typewriter face, while others may be from any type of computer printer.

The quality of this reproduction is dependent upon the quality of the copy submitted. Broken or indistinct print, colored or poor quality illustrations and photographs, print bleedthrough, substandard margins, and improper alignment can adversely affect reproduction.

In the unlikely event that the author did not send UMI a complete manuscript and there are missing pages, these will be noted. Also, if unauthorized copyright material had to be removed, a note will indicate the deletion.

Oversize materials (e.g., maps, drawings, charts) are reproduced by sectioning the original, beginning at the upper left-hand corner and contimuing from left to right in equal sections with small overlaps. Each original is also photographed in one exposure and is included in reduced form at the back of the book

Photographs inchuded in the original manuscript have been reproduced xerographically in this copy. Higher quality $6^{n} \times 9^{n}$ black and white photographic prints are available for any photographs or illustrations appearing in this copy for an additional charge. Contact UMI directly to order.

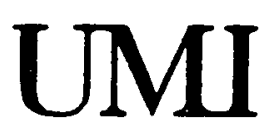

A Bell \& Howell information Company 



\title{
A PILOT STUDY DESCRIBING
}

\section{NEUROLOGIC ASSESSMENT TOOLS USED \\ BY SCHOOL NURSES TO DETERMINE}

AT-RISK LEARNERS IN THE GRADE SCHOOL POPULATION

\author{
A Thesis \\ Presented to \\ The Faculty of the School of Nursing \\ San Jose State University \\ In Partial Fulfillment \\ of the requirements for the Degree \\ Master of Science
}

by

Carol Pette Bergner

December, 1995 
UMI Number : 1377210

Copyright 1995 by Bergner, Carol Pette

All rights reserved.

UMT Microform 1377210

Copyright 1996, by UMI Company. All rights reserved.

This microform edition is protected against unauthorized copying under Title 17, United States Code.

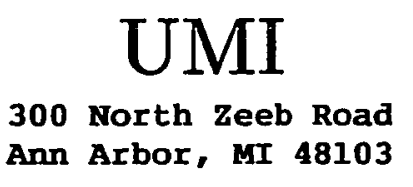


(c) 1995

Carol Pette Bergner

ALL RIGHTS RESERVED 
APPROVED FOR THE SCHOOL OF NURSING

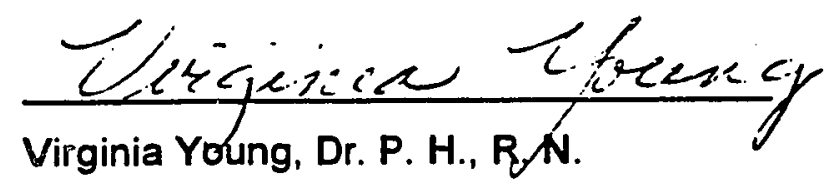

Elizabeth OD at

Elizabeth O. Ditz, Ed. D, R. N., C. S.

All un Dfundilin

John D. Laughlin, M. Ed.

APPROVED FOR THE UNIVERSITY

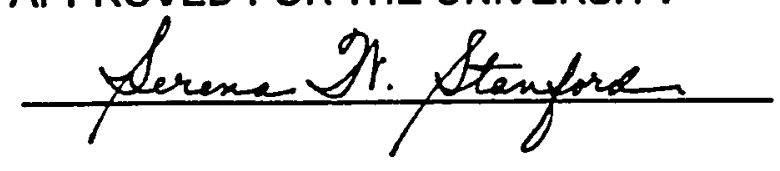




\begin{abstract}
A PILOT STUDY DESCRIBING NEUROLOGIC ASSESSMENT TOOLS USED

BY SCHOOL NURSES TO DETERMINE AT-RISK LEARNERS IN THE GRADE

SCHOOL POPULATION

by Carol Pette Bergner
\end{abstract}

Deficits in neurological maturation and development have specific positive correlation with academic difficulties. Early assessment and identification of children with these problems have allowed for remediation and prevents the development of secondary problems. The purpose of this pilot study was to determine whether or not school nurses have been screening for neurological deficits, which tools have been used to assess this aspect of development, how results "are" or "could be used", and what school nurses opinions were in regard to the Quick Neurological Screening Test (QNST). A descriptive study design was used and data was gathered using a questionnaire.

Findings indicated that school nurses have not been routinely doing neurological screening on children at-risk for learning disabilities. The most frequently used tool was the QNST; however, only a small portion of the sample responded to this question. Reasons for non-use of neurological screening were: time constraints, role ambiguity, and lack of knowledge of neurodevelopmental screening. Recommendations for addressing these issues and opportunities for further research were proposed. 


\section{ACKNOWLEDGMENTS}

To Don, for his countless hours of proofing, computer fixes, and support; to Kathleen, for her help in tracking down references and assistance in computer graph know how, to Patrick who assisted with printing suggestions; to Sarah for her continued understanding and encouragement throughout; and, to John for his library expertise. 


\section{TABLE OF CONTENTS}

Page

LIST OF TABLES

ix

LIST OF FIGURES

$x$

Chapter

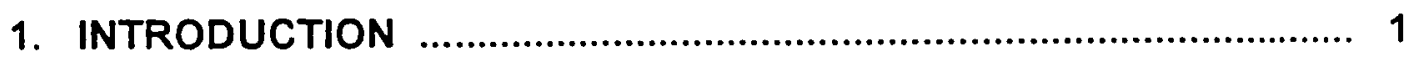

Purpose and Need ....................................................................... 2

The Research Problem .............................................................. 2

The Research Question ................................................................ 4

Definition of Terms .................................................................. 5

Research Design ................................................................... 9

2. CONCEPTUAL FRAMEWORK AND REVIEW OF RELATED

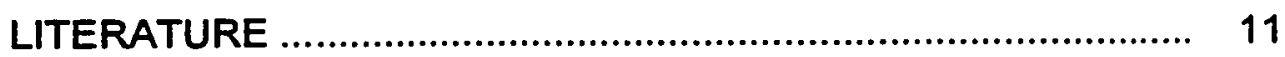

Introduction .......................................................................... 11

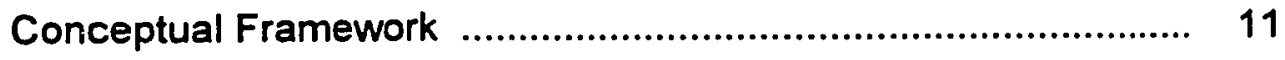

Neurological Classifications ..................................................... 14

Learning Disabilities .................................................................. 15

Screening \& Assessment Tools ................................................. 20

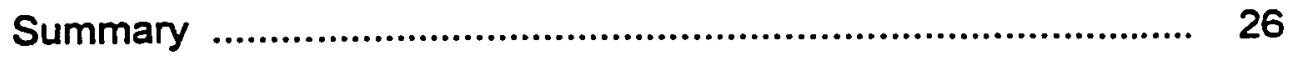


$\begin{array}{ll}\text { Chapter Page } & \text { Pag }\end{array}$

3. THE METHOD …................................................................ 28

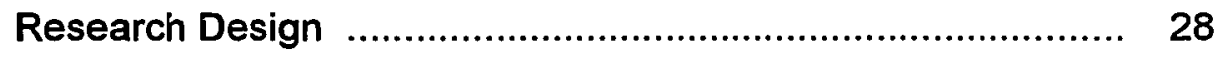

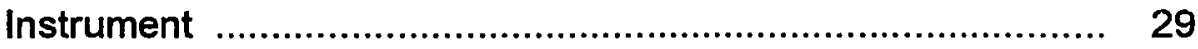

Human Subject Approval ............................................... 30

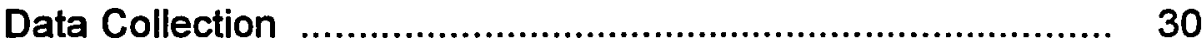

Analysis of the Data ............................................. 31

4. ANALYSIS AND INTERPRETATION OF DATA ......................... 33

Description of the Sample ........................................... 33

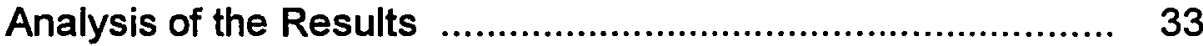

Summary of Results ................................................. 46

5. CONCLUSIONS AND RECOMMENDATIONS ............................ 47

Conclusions ….......................................................... 48

Limitations .............................................................. 50

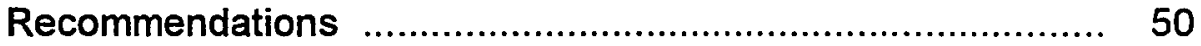

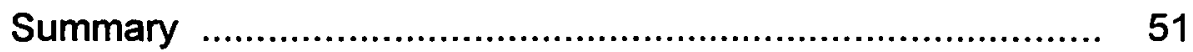

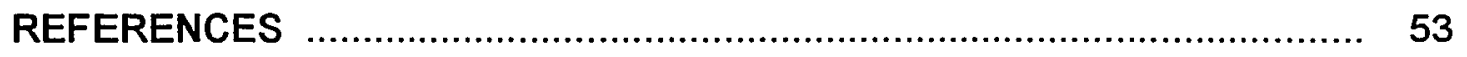




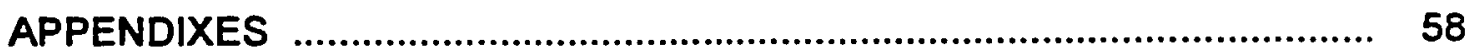

A. Consent Letter .............................................................. 58

B. Data Collection Form .................................................... 60

C. Permission Letter A ....................................................... 64

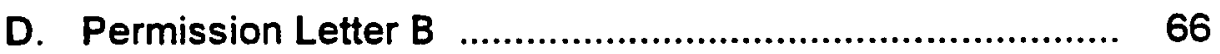

E. Human Subjects Application ........................................... 68 


\section{LIST OF TABLES}

\section{Table}

Page

1. Demographic Characteristics of Sample ..................................... 34

2. Population being Served ............................................................. 37

3. Screening Exams Performed …................................................. 38

4. Neurological Screening Tools Used ……………........................... 39

5. Student Study Team, Nurse Participation ..................................... 40

6. How results of neurologic screenings are used .......................... 41

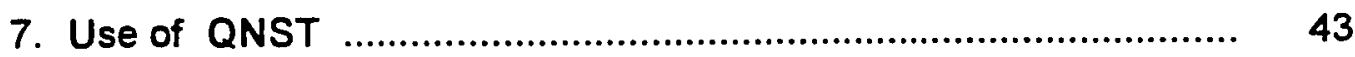




\section{LIST OF FIGURES}

Figure

Page

1. Reasons School Nurses Do Not Use

Neurological Screening Tools

45 


\section{Chapter 1}

\section{INTRODUCTION}

Modern medical practices have prevented and reduced severe handicapping conditions in the at-risk infant population. The number of term, pre-term, and small for gestational age (SGA) infants has increased the number of at-risk infants who survive the neonatal period and reach childhood without serious developmental disabilities (Widerstrom, Mowder, \& Sandall, 1991). This change has occurred because of improved technology in neonatal care and development of early intervention strategies. The National Center for Health Statistics (NCHS)(1990) has proposed that the increase in childhood learning and behavior problems may be caused by the increased survival rate of extremely low-birthweight babies, the possible effects of environmental contamination, and/or the rising numbers of babies born to crack-addicted mothers. Although the precise cause has not been identified, research has indicated that the prevalence of minor neurodevelopmental and neurobehavioral delays has been increasing (Widerstrom et al., 1991). Despite the prognosis for normal neurodevelopmental outcome in neonatal intensive-care unit survivors has improved, "10 to 55 percent may demonstrate neurologic or developmental impairment (or both), depending on the gestational age and hospital course" (Swanson \& Berseth, 1987, p. 617). 


\section{Purpose and Need}

A substantial rise in identification of learning disabilities as children reach school age has been noted. Learning disabilities, in contrast to developmental delays, have been hidden handicaps that become apparent at school age when the child starts trying to read, write, and calculate (NCHS, 1990). The proportion of children with learning disabilities increases from 1.6\% at ages 3 to 5 years to $6.8 \%$ in the elementary school ages 6 to 11 years, with a further increase to $8 \%$ at ages 12 to 17 years (NCHS, 1990, p. 5). These deficits have been shown to be chronic, persistent, and permanent. 'Minimal 'soft signs' in children tend to present various cognitive and behavioral deficits in adulthood that restrict their training and vocational opportunities" (Gaddes \& Edgell (1994), p. 476).

The Research Problem

Deficits in neurological maturation and development have specific positive correlation with academic difficulties. Early assessment and identification of children with these problems allow for remediation and prevent the development of secondary problems. Without early identification and intervention, the young learner faces problems resulting from these deviations that become more serious as time goes on, because they affect the developmental foundations for learning and behavior (Mutti et al., 1978, p. 23). When these difficulties have not been addressed, “additional learning becomes distorted. Incorrect perceptions, poor learning skills, and the inabiltiy to conceptualize have a cumulative effect and result in increasingly uneven development " (Mutti et al., 1978, p. 23). 
In addition to the educational implications, Connolly (1978) has described two basic human needs that have been threatened by learning disabilities: the need to be accepted and the need for competence (Wold, 1981, p. 201). Children have been known to transfer failure in the area of schoolwork to a sense of failure in other areas with resulting low self-esteem. Repeated failures have caused many children to stop trying or to avoid situations related to learning (Lewis \& Thomson, 1986, p. 171). Failure to achieve has also meant failure for some to gain peer acceptance (Wold, 1981, p. 201). Lack of acceptance has led some students to become isolated from their peers with a resulting maladaptive life-style. Chronic school failure has been shown to result in anxiety and depression, leading to school absenteeism or resignation (Jackson \& Vessey, 1992, p. 363).

Another significant consideration for school nurses has been the high incidence of school age children having both learning disabilities and other health problems. The NCHS (1990) found that " $35 \%$ of children between ages 3 to 17 years who were described as having poor or fair health had a developmental, learning, or behavioral problem" (NCHS, 1990, p. 3).

This pilot study has described the neurologic assessments school nurses have used to identify those students who are at-risk for these problems. The Quick Neurological Screening Test (QNST) has interested this researcher because it "allows the examiner to sample, in an orderly way, how the child monitors and integrates sensory information from visual, tactile, auditory, and 
proprioceptive or kinesthetic sources" (Mutti, Sterling \& Spalding, 1978, p. 37). Because this test takes approximately 30 minutes to administer and score, it has lent itself well to the busy schedule of a school nurse. In addition, referral criteria have been clearly outlined based on the individual's score. This test has been in use since 1978 and has become an accepted instrument for screening neurological development in children.

The QNST was designed as an individual test that assesses neurological integration as it relates to learning. "The test consists of a series of brief tasks, adapted from a pediatric neurological examination, which are easy for the prospective examiner to master and which are not threatening to the subject" (Mutti et al., 1978, p. 5). The 15 subtests from the QNST have been included with the survey questionnaire to determine if school nurses have been using the QNST and to obtain their assessment of its usefulness in their practice.

\section{Research Questions}

Screening for neurological deficits was identified as an area to be viewed from the school nurse perspective because of the following reasons: (a) the large number of school-age children experiencing these problems, (b) the chronic nature of learning disabilities, (c) the high correlation of other heath problems co-existing with learning disabilities, (d) the need for early identification and remediation, and, (e) the negative influence LDs can have on the developing child's self image. The purpose of this study was to determine whether or not school nurses have been screening for neurological deficits, 
which tools are currently being used to assess this aspect of development, how results "are" or "could be" used, and what school nurses' opinions were in regard to the Quick Neurological Screening Test (QNST). The following research questions have formed the basis of this pilot study.

1. What neurological assessments are school nurses currently using to screen neurologic function in the school age population?

2. What are the opinions of school nurses regarding the QNST?

3. How is the QNST used in school nursing practice?

4. If the QNST is now not being used, how might it be used in school nursing practice?

\section{Definition of Terms}

The following terms are defined for the purpose of this study:

1. Apraxia is the inability to plan and/or perform purposeful motor acts (California School Nurses Organization [CSNO], 1993).

2. Ataxia is the muscular incoordination of voluntary muscles (CSNO, 1993).

3. Attention is the ability to select a purposeful stimulus on which to concentrate for a reasonable length of time (CSNO, 1993).

4. Auditory perception is the ability of the brain to discriminate sounds from each other and to identify meaningful units of sound (Levine, Brooks, \& Shonkoff, 1980). 
5. Auditory sequential memory is the brain's capacity to retain in the right order a span of information presented orally (Levine et al., 1980).

6. Cerebral palsy is a static neurological deficit that can result from a neurological insult prior to, during, and following birth (CSNO, 1993).

7. Choreiform pertains to involuntary, rapid, irregular movements of the limbs or facial muscles (Lewis \& Thomson, 1986).

8. Diadochokinesia is the performance of alternating, rapid movements in succession (CSNO, 1993).

9. Dysgraphia is the inability to produce the motor movements necessary for handwriting. May be part of a language disorder caused by a disturbance in the parietal lobe or in the motor system (CSNO, 1993).

10. Expressive lanquage function is the ability to code ideas into words, phrases, and sentences (Levine et al., 1980).

11. Fine motor function is the ability to use small muscle groups efficiently, smoothly, and quickly (Lewis \& Thomson, 1986).

12. Finger agnosia is the loss of ability to indicate one's own or another's fingers in the absence of visual cues (CSNO, 1993).

13. Gross motor function is the ability to move large muscles in a coordinated and efficient manner (Lewis \& Thomson, 1986).

14. Impulsivity is the tendency to act without considering the consequences (Lewis \& Thomson, 1986). 
15. Laterality is the ability to distinguish between right and left and to control the two sides of the body together or separately (CSNO, 1993).

16. Learning disability is a group of disorders manifested by significant diifficulties in listening, speaking, reasoning, reading, and writing (Lewis \& Thomson, 1986).

17. Motor impersistence is an inability to maintain a posture or sustained activity over a given period of time (Levine et al., 1980).

18. Minimal brain dysfunction is a descriptive medical term for children with near average, average, or above average intelligence quotient (IQ) who have certain learning or behavioral disabilities ranging from mild to severe that are associated with deviations of the central nervous system's function (Lewis \& Thomson, 1986).

19. Neurodevelopmental examination is an integral aspect of a well child examination in which assessment of the nervous system's maturation level and developmental status in a variety of areas, including fine and gross motor function, visual perception, and auditory language ability (Lewis \& Thomson, 1986).

20. Neurological "hard signs" are signs that indicate disease of the nervous system or a brain lesion, e.g. nystagmus, strabismus, equivocal abnormal reflexes (CSNO, 1993).

21. Neurological "soft signs" are a series of findings on examination that indicate inefficient or immature function of the central nervous system. These 
signs represent a kind of "window" of the degree of development of the nervous system (Levine et al., 1980).

22. Perception is the recognition and appropriate interpretation of stimuli received in the brain (Lewis \& Thomson, 1986).

23. Perceptual motor skills are those skills which indicate the interrelationships between the perceptual or sensory processes and motor activity and the ability of the individual to receive, interpret, and respond accurately to stimuli, either internal or external (CSNO, 1993).

24. Perseveration is the continuation of an activity, response, or reply after the causative stimuli have ceased (Lewis \& Thomson, 1986).

25. Processing disorder refers to a category of specific learning disabilities in which the child has difficulty interpreting and integrating information in a timely and appropriate manner (CSNO, 1993).

26. Proprioception is a perceptual process whereby data from sensory nerve endings in joints allow one to acquire information about body position or the location of individual parts of one's own body in space (CSNO, 1993).

27. Public Law 94-142, the Education for All Handicapped Children Act, became law in 1975 and was fully implemented in 1980. The law states that all handicapped children between the ages of 3 and 21, regardless of the type or severity of their disability, shall receive a "free, appropriate public education which emphasizes special education and related services designed to meet their unique needs" (Whaley \& Wong, 1995). 
28. Receptive language function is the ability to process and understand verbal information auditorily (Levine et al., 1980).

29. Screening is the process of testing children to identify those children needing further evaluation, diagnosis, and treatment (Glascoe, Martin \& Humphrey, 1990).

30. Sensory interpretation is the nervous system's conscious process of assimilating and organizing stimulus obtained through the senses; perception (of stimulus) (CSNO, 1993).

31. Sequencing ability is the ability to get things in the right order; pervades many sensory, perceptual, and motor processes and there are visual sequences, auditory sequences, and sequences for complex motor activities (CSNO, 1993).

32. Synkinesis (mirror movements) occurs when one side of the body mimics an activity performed on the contralateral side (CSNO, 1993).

33. Tactile pertains to the sensation of touch (Lewis \& Thomson, 1986).

34. Visual-motor function is the ability to coordinate vision with movements of the body or body parts (Lewis \& Thomson, 1986).

35. Visual perceptual disability presents a difficulty in organizing and interpreting visual sensory stimuli (Lewis \& Thomson, 1986).

36. Visual sequential memory is the storage of and retrieval of visual information from memory (Lewis \& Thomson, 1986). 


\section{Research Design}

This research pilot study used a descriptive study design. The data gathering tool determined what neurologic assessment tools school nurses have used to evaluate the neurologic status of students at risk for learning disabilities in the grade school population. The data collection tool was a survey questionnaire developed by this researcher. The questionnaire included questions on demographic information, questions on current practice in the use of neurological screening tools, attitudes regarding the need for neurologic screening, and opinions as to whether or not the QNST is seen as being helpful. 


\section{Chapter 2}

Introduction

This chapter has included a conceptual framework and a literature review that has topics of neurological classifications, learning disabilities, and neurologic screening tools. The literature review has spanned 30 years as there has been little evidence of current or past documentation in the literature specific to the research questions.

\section{Conceptual Framework}

Piaget's theory of child development explained that a child is in a continual process of adaptation (Pothier et al., 1983). The reflex mechanisms of the newborn gradually become integrated with the nervous system through maturity. "The growth of intelligence in the child is viewed as a progressive transformation of voluntary sensory motor actions into thought patterns through interaction with concrete objects" (Pothier et al., 1983, p.74). According to Ayres, "Integrative processes occur in all levels and areas of brain function, but those connected with sensorimotor integration are basic to all learning and mental function" (Gaddes \& Edgell, 1994, p. 58). Sensory motor dysfunctions have been shown to occur on a continuum with learning disabilities a mild expression of these deficits. These minor neurologic impairments have been referred to as "soft signs" and have been manifested by lack of physical coordination, abnormal tactile sensitivity, poor motor planning, poor body image, 
poor spatial relations, and academic difficulties (Pothier et al., 1983). "Though the causes of learning problems are not known, a disturbance in sensorimotor integration seems to be present in a number of them" (Gaddes \& Edgell, 1994, p. 97).

Behavior, as the product of the nervous system, can be understood fully only in relation to the functioning of the nervous system (Staddon \& Bueno, 1991). The theory of sensory integration has been a theoretical framework traditionally used to explain nervous system functioning in the learning disabled student. Sensory integration theory was pioneered in the 1950's by A. Jean Ayres and explained the importance of basic sensory perception in understanding the functioning of the central nervous system. "Sensory integration is rooted in the concept that individuals follow a set sequence in the development of skills with failure to master these stages in a sequential pattern resulting in poor neurologic organization" (Jackson \& Vessey, 1992, p. 362).

This theory was based on the belief that higher cortical functions were dependent upon adequate neuro-organization at more primitive brain levels (Levine et al., 1980, p. 206). Sensory integration was hierarchic in design and required intraorganic integration free of stresses. "A deficit in integration can produce learning problems at different levels" (Gaddes \& Edgell, 1994, p. 87). Ayres' studies of children with learning diabilities revealed inadequate sensory integration at the brain-stem level, demonstrated in "immature postural 
reactions, poor extraocular muscle control, poorly developed visual orientation to environmental space, difficulty in processing sound into precepts, and a tendency toward distractibility" (Levine et al., 1989, p. 206). Research has shown that "organization of auditory and visual processes by brain-stem structures, as well as, the prerequisite normalization of postural mechanisms in the midbrain, are necessary for higher-order learning to proceed" (Levine et al., 1980, p. 206).

Ayres's theory and remediation approach of sensory integration addressed several of the problems exhibited by children with neurologic "soft signs". The following assumptions were the basis of her theory: (a) sensory integration takes place in normal development as information is taken in through the senses and is the process by which the central nervous system develops; (b) this process begins in infancy and continues until the child is between 8 and 10 years old, but continues to be refined throughout life; (c) it occurs on an unconscious level whereas thinking and cognition are conscious processes; and, (d) this development is enhanced by sensory experiences (Ayres, 1979).

The purpose of sensory integrative therapy was "to enhance the child to develop and learn through more efficient neural processing" (Pratt \& Allen, 1989, p. 485). Treatment provided a situation in which the "child can receive and respond to meaningful sensory input, and environmental challenges involving motor planning, ideation and problem-solving" (Pratt \& Allen, 1989, p. 485.). 
Neurological Classifications

Cerebral dysfunction has been characterized by perceptual, cognitive, and/or motor impairments. Gaddes' (1976), comments argued that all behavior has been mediated by the central nervous system (CNS) and its integrated and supporting physiological systems (Obrzut \& Hynd, 1987, p. 596). Increasing evidence has supported the connection between learning problems with accompanying neurological soft signs and frank brain damage. "Both may be points on a continuum of cerebral dysfunction, with the physiological and structural aspects of learning disability being too subtle to be detected by currently employed medical diagnostic methods" (Moehle \& Fitzhugh-Bell, 1989, p. 123).

Neurological impairment signs and symptoms have been classified both as "hard signs" and "soft signs". Neurological "hard signs" have been manifested in obvious disabilities and have been characterized by: motor impersistence, choreiform syndrome, asymmetry of deep tendon reflexes, "hyperactive" deep tendon reflexes, awkward postures of gait, tremors, ataxia, nystagmus, strabismus, abnormalities or asymmetry of muscle tone, and abnormal reflexes (CSNO, 1993).

Neurological "soft signs" have been found to be irregularities in assessing central nervous system dysfunction in children. "These 'soft signs' have been characterized by: fine, subtle, minor symptoms, which are observable in mild 
coordination difficulties, minimal tremors, motor awkwardness, visual motor disturbances, abnormal delay in speech development, and difficulties in reading and arithmetic" (Spalding \& Geiser, 1978, p. 316). "Various studies suggest ... that soft neurological signs can be demonstrated in $65 \%$ to $70 \%$ of children with school problems" (Smith \& McNamara, 1984, p. 232). Children with multiple "soft signs" have been believed by some researchers to be exhibiting a very mild form of cerebral palsy. However, "soft signs" have been insufficiently discriminating to be employed in making a formal diagnosis (Smith \& McNamara, 1984).

\section{Learning Disabilities}

The actual percentage of school age children who experience learning disabilities has been disputed by experts. This dispute has been due to the many different ways in which the definition of learning diabilities can be interpreted, the different means of diagnosing and identifying learning disabled children, and the unreliable assessment instruments used to diagnose learning diabilities (Heyward \& Orlansky, 1988). Some experts have given the range as anywhere from $5 \%$ to $40 \%$ of the total population; however, most experts believe a realistic estimate is $10 \%$ to $20 \%$ (Goldstein et al., 1981, p. 452 ). Based on estimates by the National Institutes of Health, The National Center for Learning Disabilities (1995) reports that $15 \%$ of the United States population have some form of learning disability. According to Gaddes \& Edgell (1994), learning 
disabilities in the United States, Europe, and Canada, involve about $15 \%$ of the student population.

The literature contained many definitions and labels to describe learning disabilities and, it is clear that learning disabilities have been expressed as a wide range of symptoms. Terms that have been used to describe these lowseverity handicaps have been: minimal brain dysfunction, dyslexia, brain injury, and aphasia (Wold, 1981, p. 200). In 1975, the passage of Public Law (P.L.) 94142, the Education for All Handicapped Children Act, attempted to standardize the definition of learning disabilities and adopted the definition proposed by the National Advisory Committee on Handicapped Children of the U. S. Office of Education. This has been the most widely accepted definition of learning disabilities and it reads:

Specific learning disability means a disorder in one or more of the basic psychological processes involved in understanding or in using language, spoken or written, which may manifest itself in an imperfect ability to listen, think, speak, read, write, spell, or to do mathematical calculations. The term includes such conditions as perceptual handicaps, brain injury, minimal brain dysfunction, dysiexia, and developmental aphasia. The term does not include children who have learning problems that are primarily the result of visual, hearing or motor handicaps, of mental retardation, or, of environmental, cultural, 
or economic disadvantages (Section 5(b)(4) of P.L. 94-142) (Heward \& Orlansky, 1988, p. 129).

Explanations for causative or etiologic factors of learning disabilities (LDs) have been varied. No definitive cause of neurolgic dysfunction resulting in LD has been identified at this time. Nevertheless, explanations have usually fallen into three categories: brain damage, biochemical imbalance, and environmental factors (Heward \& Orlansky, 1988).

Cruickshank (1977) has offered a cause and effect explanation of LDs which states that LDs have been caused by the direct result of perceptual processing deficit. "Perception and perceptual processing are neurologically based" (Heinlein, 1980, p. 15). In the presence of a perceptual processing deficit, there must be a neurological deficit or dysfunction, whether or not a definitive neurological diagnosis has been made (Heinlein, 1980).

Levine (1987), however, has proposed a multifactorial perspective. He has viewed the child as, "a product of diverse constitutional predispositions interacting with multiple exogenous factors that make narrow notions of etiology and a discrete reason for the child's difficulty unlikely" (Levine, 1987, p. 7). Clear, causal relationships have been difficult to determine, but rather there was found to be an "interaction with preexisting central nervous system strengths and dysfunction as well as with other environmental conditions and life experiences to shape developmental outcomes in later childhood" (Levine, 1987, p. 7). 
Gaddes and Edgell (1994) have suggested that constitutional causes underlie deficits in learning. These causes have not been fully understand but may result from: (a) an abnormal brain structure, (b) genetic defects, (c) some form of neurotoxicity or body-chemistry imbalance, (d) minimal brain dysfunction so obscure as to be to undetected on standard neurological examination, or (e) some other neuro-physiological cause unknown at present (Gaddes \& Edgell, 1994, p. 15).

Familial tendencies have been noted in the occurrence of LDs and genetic influences may have a role in the development of LD (Heinlein, 1980). No gene for learning disabilities has been isolated but there may be genetic correlates that produce specific neuropathology. Galaburda (1988) studies have revealed that there is a symmetry of the temporal plane, asymmetric (left more than right) cortical nerve cell anomalies (changes that occur between the 18th and 24th week of gestation), which cause more nerve cells to develop in the right hemisphere (Drake, 1989). The unusual nerve cell migration defects "influence the left more than the right hemisphere because of the slower rate of left-hemispheric embryonal evolution as contrasted with the right" (Drake, 1989, 219). Decker (1984) found that "the risk factor for reading disability is increased substantially (by a factor from about 4 to over 13) if either parent has had difficulty in learning to read" (Levine, 1987, p. 399). This finding suggests that 
family history information should be included in a multifactorial risk assessment for LD.

Problems during pregnancy and birth have resulted in learning disabilities. Wold (1980) has referred to retrospective studies that have shown that more mothers of children with LDs experienced complications of pregnancy than mothers of children without LDs (Wold, 1980, p. 205). Complications of pregnancy that may contribute or cause LD are: (a) maternal illness (i.e. diabetes) or injury; (b) maternal use of drugs or alcohol; (c) RH incompatibility with the mother (if untreated); (d) premature or prolonged labor resulting in lack of oxygen, or low birth weight (National Center For Learning Disabilities, 1995).

Trauma and insults to the brain following birth have been implicated in the genesis of LDs. Incidents after birth such as head injuries, infections, nutritional deprivation, exposure or ingestion of poisonous substances, and child abuse have also led to LDs. Environment and low socio-economic status have been implicated as serious stressors to the developing child and some consider these stressors to influence neurologic outcomes significantly.

There has been a trend in education to identify a neurodevelopmental basis for the condition known as LDs (Finlayson \& Obrzut, 1993). The neurodevelopmental focus has become the educational alternative to the diagnosis of minimal brain dysfunction. There has been an increasing tendency to divorce manifestation of LDs from etiology and to define it in behavioral and 
educational terms (Heinlein, 1980). Specific deficits in perceptual processing in otherwise normal children have been designated LDs. According to Heinlein, the most frequently cited specific behavioral characteristics have been:

hyperactivity; perceptual-motor deficits; emotional liability; general orientation and laterality defects; disorders of attention such as distractibility and short attention span; impulsivity; disorders of memory and conceptual thinking; specific learning defects, particularly language deficits. Some of these symptoms have been found in all children at some time during their development. However, a child with a cluster of these problems should have further examination for a possible diagnosis. The neurodevelopmental basis has focused on identifying the child's specific needs to provide remediation strategies.

Screening \& Assessment Tools

Historically, psychological assessment has been traced to passages written by Plato in Ancient Greece 2,500 years ago, and in Ancient China 200100 BC years ago (Matarrazzo, 1990). These earliest tests were used to select the most able applicants for civil service positions. More currently, in the 1900's, Alfred Binet and Theodore Simon, constructed the first modern psychological examinations for children and adults (Matarrazzo, 1990).

Today, school psychologists have been primarily responsible for testing and incorporating findings from other clinicians to make a diagnosis of LD. "LDs are diagnosed when the individual's achievement on individually administered, 
standardized tests in reading, mathematics, or written expression is substantially below that expected for age, schooling, and level of intelligence" (American Psychiatric Association, 1994, p. 46). Psychologists diagnosing LDs have to consider several factors: (a) differences in normal variations in academic attainment, (b) delays related to poor teaching practices, (c) lack of opportunities, and, (d) cultural factors. The phenomena causing the discrepancy have been unknown but hypothesized to stem from neurological dysfunction, perceptual and/or perceptual-motor dysfunction, and psycholinguistic dysfunction (Fabian \& Jacobs, 1981).

School psychologists have used a variety of standardized psychometric tests to measure and evaluate the child's intellectual and cognitive processes. Two commonly used tests have been: the Weschsler Intelligence Scale for Children - Revised (WISC-R), and the Wide Range Achievement Test (WRAT) Revised (Love, 1985). The WISC-R was designed to assess intellectual capacity in children ages 6 to 17 years (Lewis \& Thomson, 1986). The 12 subtest format emphasized measurement of various types of ability in verbal and nonverbal modes. According to Sattler (1988), the WISC-R has been an excellent tool for distinguishing intelligence levels and has been the cornerstone of children's neuropsychological assessment (Matson \& Fischer, 1991, p.143). A new version of the WISC-R entitled the WISC III was developed in 1991 by D. Weschsler. It 
has only begun to replace the WISC-R in school psychology practice (J.

Laughlin, personal communication, October 24, 1995).

The WRAT has been used to evaluate sensory-motor and coding skills

related to learning to read, spell, write, and figure (Lewis \& Thomson, 1986).

Two versions of this test have been used; one for ages 5 to 11 years, the other for ages 12 to 75 years. (Lewis \& Thomson, 1986).

Diagnostic testing has required a considerable amount of time and skill on the part of the specialist administering the test. An obvious disadvantage in the assessment of childhood LDs has been that typically, by the time a child was assessed and diagnosed, the problems were firmly entrenched and this delay worked against the remediation process (Matson \& Fischer, 1991, p. 142). A screening protocol, developed for the primary educational setting, has been viewed as a possible solution to expedite the early identification of children needing further evaluation and more in-depth testing. Screening techniques that have accurately identified physical and mental handicaps in young children have been one of the most important areas of study in prevention, particularly for high-incidence, low-severity problems such as LDs (Mowder \& Sandall, 1991). There has been, however, a dearth of neurological screening tools available. "The few screening tests that exist often are directed toward specific problem types that are not applicable to a wide population where a variety of difficulties 
may be found" (Goldstein, O'Brien \& Katz, 1981, p. 451-452). Several commonly used screening tools have been discussed below.

\section{Denver II}

The Denver II has been one of the most popular screening tests. The Denver II was designed to screen children between birth and 6 years. The test has been helpful to professionals in several ways: (a) has provided a tool to measure development in children who have no symptoms of possible problems, (b) has validated professional intuitions with a standardized tool, and (c) has provided a tool that has been used to periodically check children with identified risk factors (Frankenburg et al., 1992, p. 1). Dworkin (1992) reinforced the recommendations of the test's developers that the Denver II "should serve as an effective aid to developmental surveillance, better enabling the pediatric provider to perform skilled observation of children" (Dworkin, 1992, p. 1254). The test was designed to compare a given child's performance on a variety of tasks to the performance of other children the same age (Frankenburg et al., 1992, p. 1). Casey and Swanson (1993) pointed out that it was not an appropriate expectation for a screening instrument "to predict a future developmental diagnosis such as mild mental retardation, language or articulation problems, or learning disabilities in older preschool or school-age children" (Dworkin, 1992, p. 210). Goldstein (1981) has alleged that the Denver II "was designed to identify serious developmental delays and does not identify children at risk for 
learning diabilities" (Goldstein et al. 1981, p. 452). Research by Goldstein et al., 1981, on 5 and 6-year-olds found that "children could be categorized only as being at risk for a deficit in a particular factor area rather than at risk for a learning problem in general" (Goldstein et al., 1981, p. 455).

Quick Neurological Screening Test

The Quick Neurological Screening Test (QNST) (Mutti, Sterling, \& Spalding, 1978) was a tool designed to identify those students, between the ages of 5 and 15 years, who were at-risk for learning problems. The QNST has been formatted as a brief, individual test that assesses neurological integration as it relates to the learning process. The test format was designed as a series of 15 tasks that were adopted from pediatric examinations, developmental scales, and neuropsychological tests (Finlayson \& Obrzut, 1993). Advantages to the administration of this test have been identified: (a) simple to administer, (b) nonthreatening to the student, (c) requires no elaborate equipment, (d) requires minimal training of the professional, and (e) testing and scoring combined takes approximately 30 minutes to complete. Additionally, "neurological scores are comparable to the WISC-R scores in test-retest reliability" (Mutti et al. 1978, p. 38).

The Neuro Developmental Assessment of the School Age Child The Neuro Developmental Assessment of the School Age Child was developed by the National Association of School Nurses and funded by a grant 
from Southern California Kaiser Medical Group. It was specifically designed for school nurse use in assessing neurodevelopmental status of school age children. The module format has included: developing a neurodevelopmental assessment through use of a health history, performance guidelines for completing a neurodevelopmental screening assessment, and criteria for formulating a nursing care plan. The time required by a proficient nurse examiner to complete testing has been 20 to 30 minutes. Two major disadvantages of this test have been identified: (a) there was a lack of information regarding the interpretation of results or recommendations for referrals, and (b) a three hour learning session was required to learn the module (CSNO, 1993).

\section{Nursing Neurological Instrument}

Another screening test used by nurses to evaluate children with problems in learning has been the Nursing Neurologic Instrument (NNI) developed by Paula Reynolds, R.N., M.S.N. and Eric Zurbrugg, M.D. The goal of this instrument was to determine whether a medical neurological referral was warranted. It has been used for children 3 to 13 years of age. The actual screening time has taken 10 minutes, but this time frame has not included time needed to obtain the health history and to write the report. A disadvantage noted was that the neurological screening in some areas was not adjusted for age appropriate differences. An example of this shortcoming is in the "Overall 
Cerebral Function" section in which the same questions were asked of children ages 3 to 13 years old (CSNO, 1993).

\section{Pediatric Early Elementary Examination}

The Pediatric Early Elementary Examination (PEEX) was designed as a neurodevelopmental diagnostic test for use by health professionals to assess a child for minor neurological signs, cognitive abilities, and general health. This test has been used for children who have already been identified as having significant problems in school achievement. The PEEX has been used to test motor skills, processing, linguistics and recall with children ages 7 to 9 years. It was designed for use primarily in private practice and for consultation in the schools. "Field studies of this instrument have shown a strong correlation with findings of the WISC-R and with parent and teacher ratings of behavior and learning" (CSNO, 1993, p. 122). The greatest disadvantage for school nurses utilizing the PEEX has been the lengthy time for test administration and report writing.

\section{Summary}

Considering the large numbers of children having difficulty in school, it has not been possible nor reasonable to provide a psychological examination on each child. Effective neurological screening has been shown to avoid delay caused by unnecessary referral to the school psychologist or the physician for a more complete evaluation. Screening results have been able to expedite the 
academic evaluation process and the initiation of individualized teaching strategies. The screening test has been able to identify those students who have required further evaluation and referral based on specific organic deficits detected.

The school nurse practice setting has many variations that has been shaped by grade levels served, socioeconomic factors, cultural factors, local politics, and school politics (Oda, 1991). School nurses, within their particular environment, have been in a position to include neurological screening in their practice. Inclusion of routine neurological screening has been seen as a method to meet the demands of increased enrollment of children at-risk for learning disabilities. Early identification of these students has resulted in timely intervention and remediation. 


\section{Chapter 3}

\section{Research Design}

This research pilot study has used a descriptive study design. A questionnaire was used to gather data that determined what neurologic assessment tools school nurses currently have been using to evaluate the neurologic status of students at high risk for learning disabilities in the grade school population. Additionally, the 15 subtests from the QNST were enclosed with the questionnaire. School nurses were asked their opinion concerning the usefulness of these 15 subtests in the assessment of neurological deficits in their student populations. The variables to be assessed were facts regarding current practice, attitudes regarding need for this type of screening, and opinions as to whether or not the QNST were seen as being helpful. The survey questionnaire included questions pertaining to the demographic characteristics of the respondents. The data collection tool has been included in Appendix A. This pilot survey targeted northern California urban areas where there were a large number of schools, school nurses, and numerous students who were at high-risk for learning disabilities. Six hundred nineteen school nurses working in the geographical areas served by the Bay Coast Section of the California School Nurses Organization (CSNO) were surveyed. This geographical area included the following counties: Marin, Contra Costa, San Francisco, Alameda, Santa Cruz, Santa Clara, San Luis Obispo, San Benito, 
and Monterey. All members of CSNO and non-members of CSNO who lived or practiced in this geographical area were invited to participate in this pilot survey. Instrument

The survey questionnaire, which was used as the data collection tool, was designed by the researcher for the purpose of this study. It was organized into three sections. The first section requested demographic information of those school nurses responding to the questionnaire. The second section asked specific questions about neurological assessment screening tools being used and about students being served. The third section specifically requested information about the QNST and referred to the 15 subtests of the QNST that were enclosed with the survey questionnaire.

There was a total of 12 questions in the second section; of these, questions numbered 2 through 12 required a yes or a no answer. Question \# 1 required that nurses identify age groups of students being served; more than one answer was anticipated. Questions \# 11 and \# 12 were prefaced by a check response as to whether the results 'are' or 'could be' be used followed by a yes or no format. Question \#5 asked whether routine screening for neurological functioning was being performed. Question \#6 asked if the QNST, Denver II or other neurological tests were being used for screening purposes.

The third section of the questionnaire focused on the questions pertaining to the QNST. Questions \#1 through \#5 were presented in the yes or no format 
and asked about knowledge, current usage, referral sources, and opinions about the possible uses of the QNST in practice. The last question was open ended and asked for comments on any relevant information pertaining to the pilot study questions.

The questionnaire format and content was finalized after discussion with expert peer nurses. The questionnaire was reviewed by the expert faculty advisor for the school nurse graduate program.

Human Subjects Approval

San Jose State University Human Subjects Institutional Review Board granted approval for this pilot study in February, 1995 (Appendix E). Anonymity of respondents was guaranteed. In accord with the cover letter accompanying the questionnaire, those school nurses who returned questionnaires gave permission for their responses to be used for research purposes. No names or other form of identification was attached to the returned questionnaires. The questionnaires were numbered to compare the number of questionnaires distributed with the number of questionnaires returned. The names and addresses of the respondents were obtained from the California School Nurse Organization, Bay Coast Section mailing list.

\section{Data Collection}

A total of 619 survey questionnaires were mailed. One hundred eightyfive were returned. Of those questionnaires returned, 23 were returned 
unopened as they were undeliverable. Forty returned questionnaires were not included in the pilot study since the respondents were not currently working as school nurses. The research results were based on data from 120 respondents. Not all respondents answered all questions. Frequencies and percentages have been based on the actual responses to the particular item under discussion.

A sample size of 100 subjects was the desired sample size. Since this sample size was obtained, an additional mailing of questionnaires for a larger sample was not required. The questionnaires were mailed May 5, 1995, with a two week response time frame requested.

Analysis of the Data

The demographic information was summarized. Results were given in frequencies and percentages and presented in Table 1. The survey questionnaire data have been assessed and grouped into six categories. The categories have been organized to answer the research questions. The categories were: (a) screening exams performed; (b) screening tools used to assess neurologic status; (c) student populations served; (d) the composition of the Student Study Team (SST) and school nurse participation in the SST; (e) how results of screenings "are used" or "could be used"; and, (f) knowledge, value, use, and interested in more information about the QNST. Results of each category were presented in frequencies and percentages and were shown in Tables 2 through 7 . Written comments were given as provided by the respondents in the returned questionnaires. Results were analyzed by 
content and assessed in percentages and shown in a pie graph (Figure 1), "Reasons School Nurses Do Not Use Neurological Screening". 
Chapter 4

\section{Analysis and Interpretation of Data \\ Description of the Sample}

The subjects for this pilot study were practicing school nurses residing in the geographical area served by the Bay Coast Section of the California Nurses Organization (CSNO). A mailing list totaling 619 names was obtained from CSNO. Approximately 164 of these nurses were members of CSNO; the remaining 455 , were practicing school nurses living in this area who were not CSNO members. Individual anonymity was assured and data were not associated with an individual or with CSNO membership.

A sample size of 100 subjects was the desired sample size. The actual sample size obtained was 120 , which negated the need to employ alternative strategies to obtain a larger sample size. If fewer than 75 subjects had returned surveys, CSNO, at the other section levels, would have been contacted for

further referrals or individual county or district nurses would have been invited to participate.

\section{Analysis of Results}

An analysis of the demographic data profiled school nurse respondents. School nurses who responded to the questionnaire were predominantly female, $93 \%$, and $97 \%$, held a credential to practice as a school nurse in California. Forty-nine percent had a Bachelor of Science degree which was the minimum 
educational level for a school nurse in California. Forty-four percent of the school nurses surveyed had an advanced degree. The largest group of nurses, $25 \%$, have worked 15 to 19 years as a school nurse. Most of the respondents, $83 \%$, have worked on a full time basis and, $85 \%$, have worked during the academic school year. The most frequent age group of the respondents, $39 \%$, was 51 to 60 years. The next largest age group represented, $37 \%$, was the 41 to 50 age group. The demographic data for the school nurse participants were given in frequencies and percentages and were presented in Table 1.

Table 1

Demographic Characteristics of Respondents $(N=120)$

number percent

Role

School Nurse

116

$95 \%$

Other

6

$5 \%$

Gender

Female

113

$93 \%$

Male

4

$7 \%$

California State School Health Credential

118

$97 \%$

(table continues) 


\section{Educational Background}

B.S.

MS

PhD.

Other

Years of School Nursing Experience

$0-4$

$5-10$

$10-14$

$15-19$

$20-24$

$25+$

Work Schedule

Full time

Part-time

Academic School Year

Year Round
60

$49 \%$

54

3

7

$6 \%$

18

$15 \%$

21

$21 \%$

16

$13 \%$

31

$25 \%$

18

$15 \%$

17

$14 \%$

17

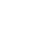

101

$83 \%$

19

$16 \%$

104

$85 \%$

17

$14 \%$ 
Age in years

20-30

$31-40$

41-50

$51-60$

$61+$
1

8

44

47

20
$1 \%$

$7 \%$

$37 \%$

$39 \%$

$17 \%$

Note: Percentages not equal to $100 \%$ have been due to rounding error.

\section{Questionnaire Results}

Nurses served many age groups in their school nurse practice. Age groups, 5 to 10 years and 11 to 14 years, were served by $103(84 \%)$ of the nurses. Most school nurses $114(95 \%)$ have worked with some special education students, but only $20(17 \%)$ have worked exclusively with special education students. The results have not totaled $100 \%$ since most respondents have worked with more than one age group and gave multiple responses. Resuits have been shown in frequencies and percentages in Table 2. 
Table 2

Population Being Served $(\mathbf{N}=120)$

Student age

$0-4$

5-10

$11-14$

15-18

19-22

Special Education students $(\underline{n}=118)$

Yes

No

Only Special Education Students
54

103

103

3

27

$22 \%$

Note: Percentages not equal to $100 \%$ have been due to rounding error. Where $\underline{\mathbf{N}}$ has not equaled 120 the number of responses has been shown as (n).

Percentages were based on either $\underline{\mathbf{N}}=120$ or on the $\underline{\underline{n}}$ indicated.

A high percentage of nurses have screened students for vision and hearing acuity (neurological processes), $97 \%$ and $91 \%$, respectively, while only 
$21 \%$ of respondents have routinely screened for neurological development.

Results have been shown in frequencies and percentages in Table 3.

Table 3

Screening Exams Performed by Respondents $(N=120)$

Screening Exams Performed $(\underline{n}=117)$

Vision

Hearing

Neurological $(\underline{n}=111)$

Routine Neurological Exams ( $(\underline{n}=112)$

Yes

No
113

$97 \%$

107

$91 \%$

25

$21 \%$

Note: Percentages not equal to $100 \%$ have been due to rounding error. Where $\underline{\mathbf{N}}$ has not equaled 120 , the number of responses has been shown as (n).

Percentages were based on either $\underline{\mathbf{N}}=120$ or on the $\underline{n}$ indicated.

One hundred twelve responded and only $12 \%$ indicated they performed routine neurological screening. Thirteen responding to the category of performing neurological screening, $100 \%(\underline{n}=13)$ used the QNST, $69 \%(\underline{n}=9)$ 
used the Denver II, with $50 \%(\underline{n}=6)$ having used other methods. Results have been shown in frequencies and percentages in Table 4.

Table 4

Neurological Screening Tools Used by Respondents $(N=120)$

Assessment Tools $(\underline{n}=13)$

\section{QNST}

Denver II

Other
13

9

6
$100 \%$

$69 \%$

$50 \%$

Note: Percentages not equal to $100 \%$ have been due to rounding error. Where $\underline{\mathbf{N}}$ has not equaled 120 , the number of responses has been shown as (n).

Percentages were based on either $\underline{\mathbf{N}}=120$ or on the $\underline{\mathrm{n}}$ indicated.

Most districts have Student Study Teams (SST), $92 \%$, but only $67 \%$ of the nurses participated regularly with $11 \%$ having participated some of the time.

Only $26 \%$ of these nurses were asked to do neurological screening for the SST. Results have been shown in frequencies and percentages in Table 5. 
Table 5

Student Study Teams (SST), Nurse Participation $(n=111)$

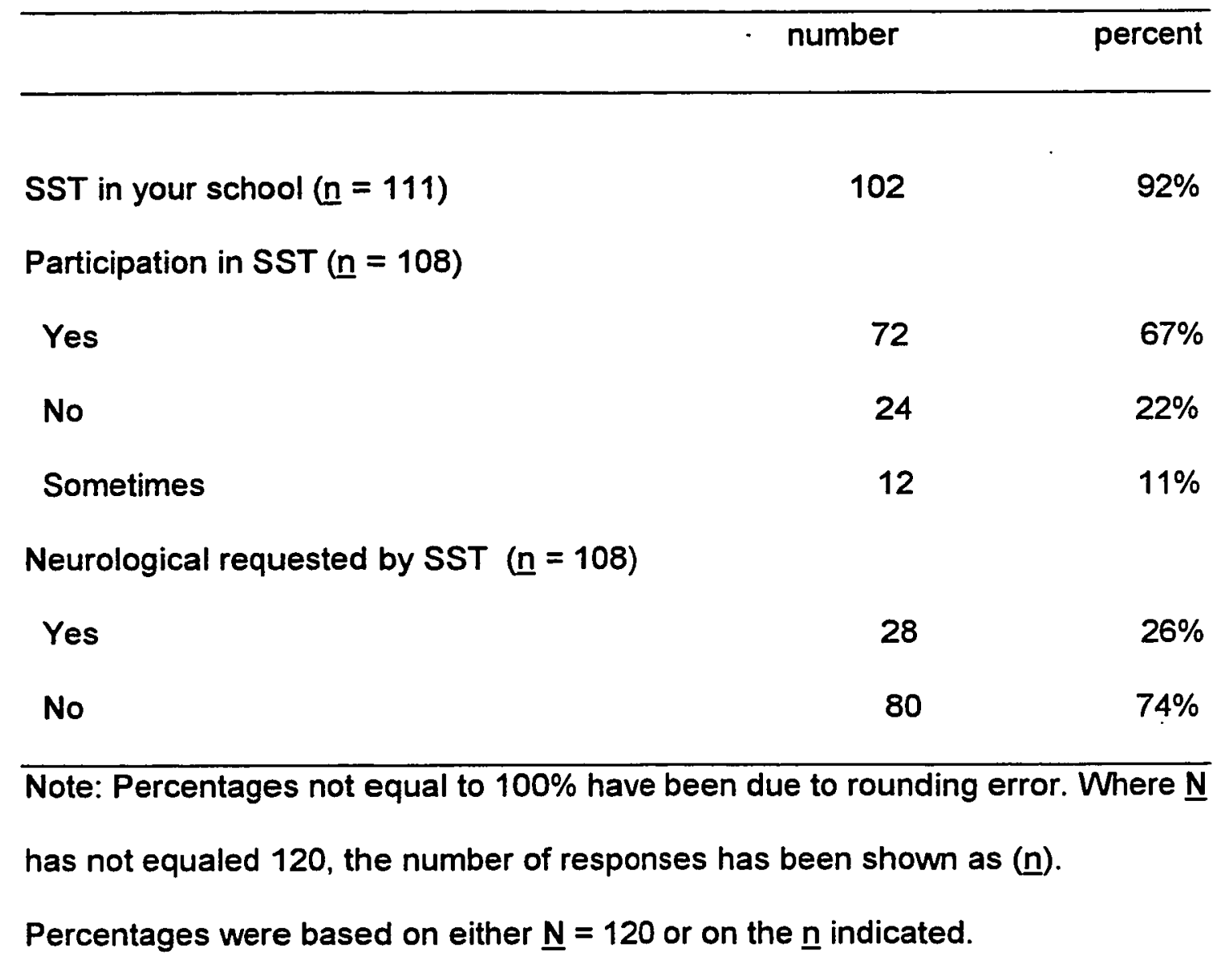

Only 15 responses were obtained for the question asking "are the results of neurological screening being used?". Of those 15 who responded, $14(93 \%)$ used the results for SST assessment. Only $12(86 \%)$ responded that they have used results for referral to a neurologist for more testing. Only 14 responses were obtained for question 11.3, which asked if testing was done to establish 
need for more extensive or more in-depth testing. Of those responding to this question, 14 (100\%) referred students for more testing. Thirteen of fourteen respondents $(93 \%)$ shared results with teachers.

Fifty-one responses were obtained for the "could be used" portion of this question. Findings found were similar to those obtained for the persons having used the neurological test results. Results have been shown in frequencies and percentages in Table 6.

Table 6

Neurologic Screening Results ( $N=120$ )

number * percent

How results of neurologic screenings are used

Assessment by SST $(\underline{n}=15)$ $14 \quad 93 \%$

Referral to neurologist $(\underline{n}=14)$ 12 $86 \%$

Establish need for more testing ( $\underline{n}=14$ ) $14 \quad 100 \%$

To assist teacher $(\underline{n}=14)$ 13 $93 \%$

How results of neurologic screening could be used

Assessment by SST $(\underline{n}=42)$ 40

$95 \%$

Referral to neurologist $(\underline{n}=46)$ 44 $95 \%$ (table continues) 
* Indicates number of yes responses.

Note: Percentages not equaled $100 \%$ have been due to rounding error. Where $\underline{\mathbf{N}}$ has not equaled 120, the number of responses has been shown as $(\underline{n})$.

Percentages were based on either $\underline{\mathrm{N}}=120$ or on the $\underline{\mathrm{n}}$ indicated.

There were 111 responses to the group of questions specific to information about the QNST. Sixty three (57\%) of school nurses surveyed have been taught the use of the QNST and $62(55 \%)$ have used this tool in the school setting. Fifty-one (81\%) of the nurses who were trained in the use of the QNST were currently using it to screen children in their schools. Of nurses who have been taught to use this test $57(85 \%)$ have self-initiated the use of this tool. Eight respondents (17\%) have used the tool without formal teaching. School psychologists were the largest group to request school nurses to perform the QNST, 30 (67\%).

Interest in knowing more about this test was shown by $43(75 \%)$ of the respondents. In addition, $44(77 \%)$ of the respondents thought that this tool could be used in their practice. Few nurses have been using the QNST 
frequently as shown by the finding that only 7 nurses have been using this tool more than 1 to 2 times every 3 months and a total of 47 nurses have been using this tool more than 1 to 2 times a year. Ninety-one percent $(n=21)$ responded that they have confidence that the QNST has been able to measure neurological functioning. Results are shown in frequencies and percentages in Table 7.

Table 7

Use of QNST $(N=120)$

number * percent

Have been taught use of QNST ( $\underline{n}=111$ )

$63 \quad 57 \%$

Have used the QNST $(\underline{n}=113)$

62

$55 \%$

Taught QNST and used QNST ( $\underline{n}=63$ )

$51 \quad 81 \%$

Not taught QNST but used QNST $(\underline{n}=46)$

$8 \quad 17 \%$

Initiation of use of test

Self initiated $(\underline{n}=67)$

$57 \quad 85 \%$

Request by psychologist $(\underline{n}=45)$

$30 \quad 67 \%$

Request by teacher $(n=40)$

$19 \quad 48 \%$

Request by parent $(\underline{n}=33$ )

$8 \quad 24 \%$

Other $(\underline{n}=14)$

$10 \quad 71 \%$

Want to know more about QNST $(\underline{n}=57)$

$43 \quad 75 \%$

Think you can use QNST $(\underline{n}=57)$

$44 \quad 77 \%$

(table continues) 
number * percent

Think they can use test in practice $(\underline{n}=57$ )

$44 \quad 77 \%$

Confidence in neurological measure $(\underline{n}=23)$

$21 \quad 91 \%$

Frequency of Use

1-2 times a month

2

$\mathrm{n} / \mathrm{a}$

1-2 times every 3 months

5

n/a

1-2 times every 6 months

14

$\mathrm{n} / \mathrm{a}$

1-2 times a year

26

$n / a$

* Indicates number of yes responses.

Note: Percentages not equal to $100 \%$ have been due to rounding error. Where $\underline{\mathbf{N}}$ has not equaled 120 , the number of responses has been shown as (n).

Percentages were based on either $\underline{\mathbb{N}}=120$ or on the $\underline{\mathrm{n}}$ indicated.

The last survey question asked for comments regarding neurological assessment. A total of 38 responses were obtained. The responses were categorized into five groups that explain lack of usage of neurological screening by school nurses. The two main reasons given by $45 \%$ of the respondents to account for why neurological screenings were not routinely performed were: time constraints and number of students being served. Twenty-six percent explained 
that neurological screening was being done by school psychologist or other professionals. Another $13 \%$ stated that they needed more education and training in the use of neurological screening methods. Seven percent expressed that the age of their students being served (high school and older) were not age appropriate for neurological screening. Another $10 \%$ gave individual reasons for not using neurological screening in their practice and these were grouped as other. Results are shown in a pie graph in Figure 1.

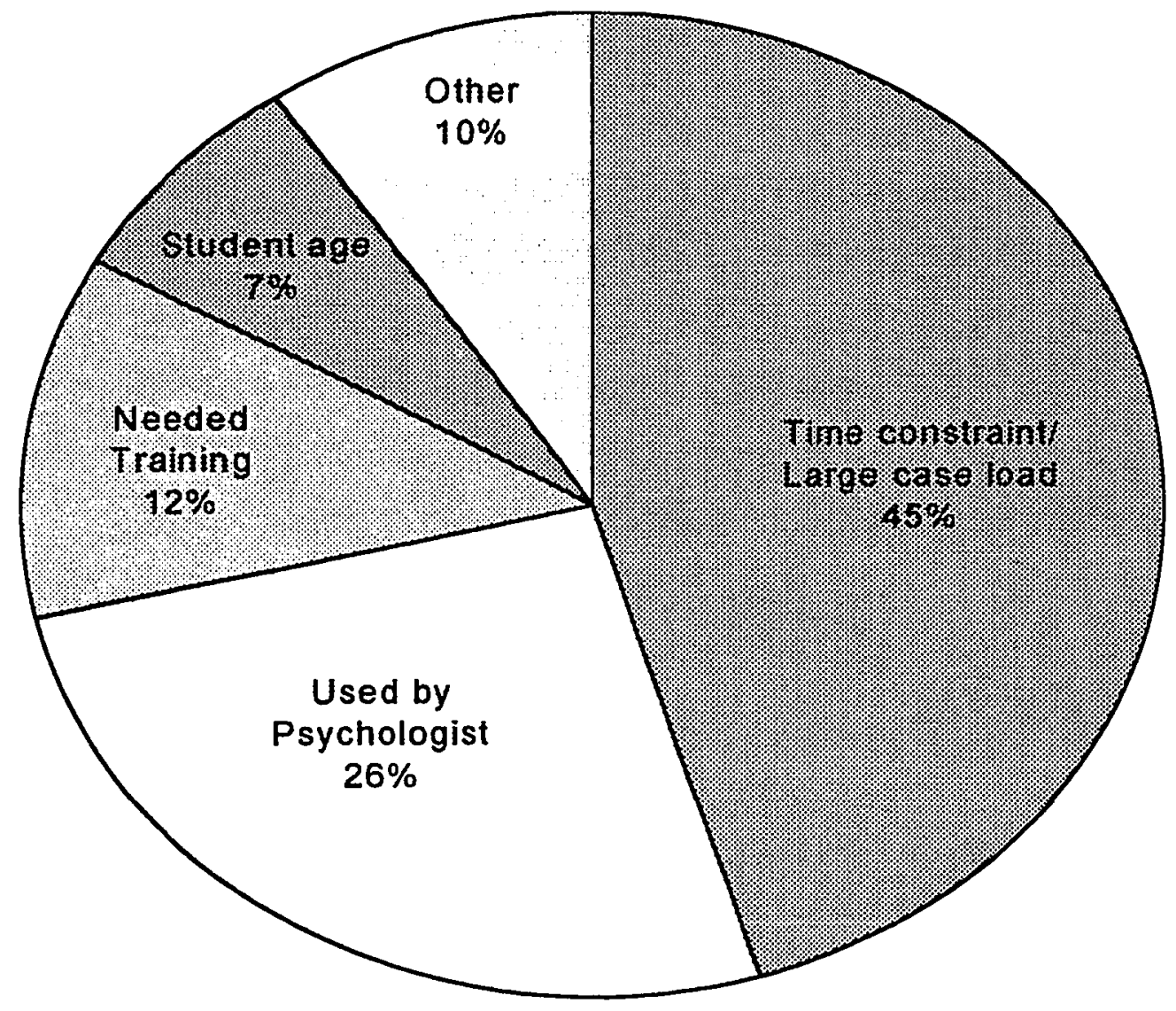

Figure 1. Reasons School Nurses Do Not Use Neurological Screening $(\underline{n}=38)$ 
Summary of Results

Very few nurses have been screening for neurologic deficits on a routine basis. Those who have been performing screenings tended to use the QNST or the Denver II. A high percentage of respondents have confidence that the QNST measures neurologic functioning in the school age child.

The two primary reasons for not having used neurodevelopmental screenings were time constraints resulting from the large numbers of students being served and from the many sites being served. The third reason given was that testing is being done by school psychologists or other professionals. The fourth most common reason given that screenings were not being performed was lack of knowledge about neurologic exams. Many nurses responded positively to learning more about the QNST. Additionally, many nurses responded that this tool has been useful in their practice. 


\section{Chapter 5}

Conclusions and Recommendations

There is a substantial rise in identification of learning disabilities as children reach school age. Approximately $15 \%$ of school age children have learning disabilities (LDs). This percentage of students represents a substantial portion of the school age population. This pilot study describes what neurological assessments' school nurses currently use to screen neurologic function in relation to the at-risk population for learning disabilities. Additionally, nurses were asked: their opinions regarding the Quick Neurological Screening Tool (QNST); about use of the QNST in practice; and, if they were not using the QNST, how might the QNST be used.

The literature attests to the fact that there is a neurological basis for learning disabilities. These minor neurologic deficits are called "soft signs" . They can be assessed by neurologic screening tools and are manifested by lack of physical coordination, abnormal tactile sensitivity, poor motor planning, poor spatial relations, and academic difficulties. These deficits have specific positive correlation to learning. The Sensory Integrative Theory, a theory based on the belief that higher cortical functions are dependent on adequate neuroorganization at the more primitive brain stem level, is offered as means of looking at learning disabilities. No definitive cause of neurologic dysfunction resulting in learning disabilities is known at this time. However, explanations 
usually fall into three groups: brain damage, biochemical imbalance, and environmental factors. Notable for school nurses is that there is a high correlation of other health problems associated with children who have known or identified learning disabilities. Learning disabilities are chronic, persistent and permanent. Early intervention is essential in preventing secondary problems that can result from the original disability and will assist children with LD's to become productive, successful adults.

\section{Conclusions}

The results of this pilot study suggest that school nurses are not routinely performing neurological screening on children at-risk for learning disabilities in the grade school population. Only $11 \%$ of the school nurses routinely screen for neurologic deficits and those school nurses that do, screen on an average of only once or twice a year in their practice. These findings are in marked contrast to the nurses performing screening for vision and hearing acuity (neurological processes), $93 \%$ and $88 \%$, respectively. These results probably reflect the California State law which mandates that students receive vision and hearing screening tri-annually.

The nurses who do screen for neurologic deficits prefer the QNST (11\%) over the Denver II (7\%) and individual tools grouped under the Other (6\%) category. However, very few of the respondents answered this question. The low response rate may not actually represent the preferred test. This low rate may 
indicate that few school nurses are routinely using neurological testing in their practice. The overwhelming majority of school nurses who have been taught the QNST include its use in their practice. However, the most frequent response to frequency of using neurologic screening is one to two times a year. Almost half of the respondents thought that the QNST would be a useful tool in their practice. Twenty-one nurses responded that they have confidence that the QNST measures neurologic functioning in the school age child.

An interesting finding shows that $92 \%$ of the respondents report that their school districts have a student study team (SST), yet only two-thirds of the respondents regularly participate. Only one-quarter of these nurses are asked to do neurological screening on students by the SST. School psychologists most frequently request neurological screening of the school nurse. This finding suggests that school psychologists do not see neurological screening by nurses as conflicting with their role in the schools.

Narrative comments to the last survey question offer some explanation for the low usage of routine neurologic screening. Approximately one-fourth of the respondents answered this question. Of those who responded half stated that the time constraints imposed by large caseloads of students ranging form 2500 4000 and the large number of schools assigned prohibited adding any further responsibilities to their work efforts. Another quarter of the respondents indicate that the screenings and testing are being done by school psychologists, other 
school professionals, and physicians. Approximately one eighth of the school nurses state that more education and training is needed to update and increase knowledge of neurological assessment.

\section{Limitations}

The limitations of this study are that only school nurses residing in the Bay Coast Section of CSNO were in the subject pool. Results may not necessarily reflect opinions of all school nurses. Another limitation of this study is that school nurses working in this geographic area may not represent the cultural diversity found in other sections of California or the United States. Results may not be generalized to other settings or populations.

Another severe limitation of this study is that so few nurses answered the questions about the use of the QNST. The small number necessitates caution in applying the results.

\section{Recommendations}

This study was designed as a pilot study, as there are no nursing studies on the specific topic under discussion. Several trends are identified and further research could proceed from this study. The information obtained from this study suggests the following recommendations:

1. Replication of the study using samples from different geographic areas to determine if the findings may be generalized to other settings.

2. Replication of this study using a larger sample population. 
3. Qualitative studies on nurses who are knowledgeable about the use and importance of neurological screening tests but who are not using these tests in their practice.

4. Qualitative studies on nurses using these tests regularly to evaluate its place in the school nursing practice.

5. Research studies on the inclusion of neurodevelopmental studies in the school nurse credential program and follow up studies to determine if changes in practice, specifically related to neurological assessment is increased.

6. Comparison studies on several neurological screening tests evaluating each for the benefit derived as compared to the length of time in administration and scoring, usefulness in identifying at-risk students, tolerance to the test by the student, and usefulness to the student study team.

Summary

School nursing is an advanced practice specialty combining specialized knowledge and skill with both pediatric and community health nursing competencies. School nursing has a broad base of practice and focuses on the well child, disabled or ill child, and the child as a part of the community. Professional school nurses are challenged by the breath and scope of their practice and role in the school environment which is constantly facing decreased funding. 
Adequate neurodevelopmental function of school-age children is essential for their progress toward becoming self-actualized adults. An expansion of practice is plausible if different priorities are used in school nursing practice. The results of this pilot study indicate that neurological deficits are found in a significant number of school age children. If school nurses regularly incorporate neurological screening of children who are at-risk for difficulty in learning, this problem will be addressed. 
References

American Psychiatric Association. (1994). Diagnostic and statistical manual of mental disorders (4th ed. rev.). Washington, DC: Author.

Ayres, A. J. (1979). Sensory integration and the child. Los Angeles, CA: Western Psychology Service.

Cruickshank, W. (1977). Learning disabilities in home, school and community. Syracuse, NY: McGraw-Hill.

CSNO Central Valley Section. (1993). History assessment neuro developmental screening option for nurses. California School Nurses Organization: Author.

Duane, D. D. (1989). Commentary on dyslexia and neurodevelopmental pathology. Journal of Learning Disabilities, $22,219-220$.

Dworkin, P. H. (1992). Developmental screening: (Still) expecting the impossible? Pediatrics, 93(6), 1253-1255.

Fabian, J. J., \& Jacobs, U. W. (1981). Discrimination of neurological impairment in the learning disabled adolescent. Journal of Learning Disabilities. 14. 594-596.

Finlayson, S. B., \& Obrzut, J. E. (1993). Factorial structure of the Quick Neurological Screening Test-Revised for children with learning disabilities. Psychology in the Schools, 30, 5-10. 
Frankenburg, W. K., Dodds. J., Archer, P., Bresnick, B., Maschka, P., Edelman, E., \& Shapiro, H. (1992). Denver II training manual. Denver, CO: Denver Developmental Materials.

Gaddes, W. H. (1976). Prevalence estimates and the need for definition of learning disabilities. In R. M. Knights \& D. J. Bakker (Eds.), The neuropsychology of learning disorders: Theoretical approaches (pp. 3-24). Baltimore: University Park Press.

Gaddes, W. H., \& Edgell, D. (1994). Learning disabilities and brain function (3rd ed.). New York: Springer-Verlag.

Glascoe, F. P., Byrne, K.E., Ashford, L.G., Johnson, K. L., Chang, B., Strickland, B. (1992). Accuracy of the Denver-II in developmental screening. Pediatrics, 89(6), 1221-1225.

Glascoe, F. P., Martin, E. D., \& Humphrey, S. (1990). A comparative review of developmental screening tests. Pediatrics, 86, 547-554.

Goldstein, P. K., O'Brien, J. D., \& Katz, G. M. (1981). A learning disability screening program in a public school. The American Journal of Occupational Therapy, $35,451-455$.

Heinlein, D. (1980). The nurse's role in helping to assess learning disabilities in the school setting. The Journal of School Health, 1, 15-17.

Heward, W. L., \& Orlansky, M. D. (1988). Exceptional children (3rd ed.). Columbus, $\mathrm{OH}$ : Merrill. 
Hurford, D. P., Schauf, J. D., Bunce, L., Blaich, T., \& Moore, K. (1994).

Early identification of children at risk for reading disabilities. Journal of Learning Disabilities, 27, 371-382.

Levine, M. D., (1987). Developmental variation and learning disorders. Cambridge, MA: Educators Publishing Service,

Levine, M. D., Brooks, R. \& Shonkoff, J. P. (1980). A pediatric approach to learning disorders. New York: Wiley.

Lewis, K. D. \& Thomson, H. B. (1986). Manual of school health. Menlo Park, CA: Addison-Wesley.

Love, H. D. (1985). Psychological evaluation of exceptional children. Springfield, IL: Thomas.

Matson, D. E. \& Fischer, M. (1991). A comparison of internalizers, externalizers, and normals using the WISC-R and the Wisconsin Card Sorting Test. Journal of Psychoeducational Assessment, 9, 140-151.

Matarazzo, J. D. (1990). Psychological assessment versus psychological testing. American Psychologist, 45, 999-1017.

Moehle, K. A., \& Fitzhugh-Bell, K. B. (1989). Factor analysis of the Conners Teaching Rating Scale with brain-damaged and learning-disabled children. Psychology in the Schools, 26, 113-125. 
Mutti, M., Sterling, H. M., \& Spalding, N. V. (1978). QNST Quick Neurological Screening Test (Rev. ed.). Novato, CA: Academic Therapy Publications. National Center for Learning Disabilities.

National Center for Learning Disabilities. (1995). General information packet on learning disabilities. New York, NY: Author.

Obrzut, J. E., \& Hynd, G. W. (1987). Cognitive dysfunction and psychological assessment in individuals with acquired brain injury. Journal of Learning Disabilities, 20, 596-602.

Oda, D. S. (1991). The invisible nursing practice. Nursing Outlook, 39. 26-29.

Pothier, P. C., Friedlander, S., Morrison, D. C., \& Herman, L. (1983). Procedure for assessment of neurodevelopmental delay in young children: Preliminary report. Journal of Child Care, Health \& Development, 9(2), 73-83.

Pratt, P. N., \& Allen, A. S. (1989). Occupational therapy for children (2nd ed.). St. Louis, MO: Mosby.

Selekman, J. (1992). Learning Disabilities. In P. L. Jackson \& J. A. Vessey (Eds.). Child with a chronic condition (pp. 355-372). St. Louis, MO: Mosby.

Smith, R. D., \& McNamara, J. J. (1984). The neurological examination of children with school problems. Journal of School Health, 54, 231-234. 
Spalding, N. V., \& Geiser, M. C. (1978). Teacher testing with the QNST. Academic Therapy, 13, 313-321.

Staddon, J. E. R. \& Bueno, J. L. O. (1991). On models, behaviorism and the'neural basis of learning. Psychological Science, 2, 3-11.

Swanson, J. A. \& Berseth, C. L. (1987). Continuing care for the preterm infant after dismissal from the neonatal intensive care unit. Mayo Clinic Practice, 62. 613-622.

U.S. Department of Health and Human Services. (1992). Developmental. learning, and emotional problems (NCHS Publication No. 190). Atlanta, GA: Author.

Widerstrom, A. H., Mowder, B. A., \& Sandall, S. R. (1991). At-risk and handicapped newborns and infants development, assessment, \& interventions. New Jersey: Prentice Hall.

Wold, S. J. (1981). School nursing. North Branch, Minnesota: Sunrise River Press.

Wong, D. L. (1995). Nursing care of infants and children (5th ed.).

St. Louis, MO: Mosby. 
APPENDIX A

Consent Letter 


\section{SISII SENWOSE

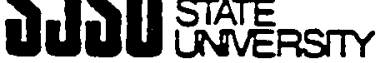

Colloge of Apphed Setences and Art - Sehod of Muring - Cretuare Progrem

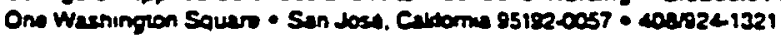

Dear School Nurse:

You are invited to participate in a research study exploring school nurses' use of neurological assessment screening tools to determine at-risk learners in the grade school population. This study, a Master's of Science degree project at San Jose State University, is a pilot study which seeks to describe those neurologic assessment screening tools used and how they are being used in practice.

Taking part in the study involves completion of a questionnaire which should take less than 20 minutes. Participation is voluntary and does not involve any risks or benefits. You will not receive any compensation for participating. If you decline to participate, it will not affect your relations with San Jose State University, or California School Nurses Organization (CSNO).

All subjects will remain anonymous. The information that you provide will be used for scientific purposes only. It may be published, but in a form in which you can never be indentified. After completion of the study, the results will be available to you upon request.

Any questions you may have about this study may be addressed to Dr. Virginia Young, (408) 924-3163. For questions or concerns regarding subjects' rights, you may contact

Dr. Serena Stanford, (408) 924-2480.

Completion and return of the questionnaire in the provided envelope within 14 days, indicates your willingness to participate voluntarijy in this study. This letter is yours to keep, as well as, the 15 subtests from the QNST Booklet which I have included for your information.

Thank you for your time, effort, and participation.

Sincerely yours,

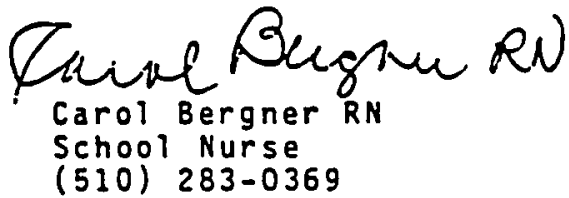


APPENDIX B

Data Collection Form 
School Nurse Demographic Information

Please place a check mark in the space before ALL ITEMS THAT APPLY.

1. Do you work as a school nurse in California?

2. In which csNoregion do you work?
Bay Coast Northern

Southern

San Diego/Imperial

3. What is/are your job title/s? School Nurse Administrator/Coordinator/Supervisor

- Administrator/Coordinator/Supervisor

4. What type of school nurse credential do you have?

4. Preliminary Professional Ciear Life

5. What is your age in years?

6. What is yourgender? $41-50$ $51-50$ $61+$

Female Male

7. What is your marital status?

8. Do you have children? Married Yes No

9. What is the highest educational level you have atta ined? BS/BA MS/MA PhD/DPH/DNS Other

10. How many years of school nursing experience do you have?

$0-4$

$$
5-10
$$
$10-14$ $15-19$ $20-24$ $25+$

11. When do you work? Academic School Year

12. Are you hired to work? Part Time(iess than 50\%)

Full Time(more than 50\%)

School Nurse Survey Questionnaire

Please place a check mark in the space before ALL ITEMS THAT APPLY.

1. How old (in years) are the students with whom you work?

$\overline{0}_{0-4}^{5-10}{ }^{11-14}{ }^{15-18}{ }^{19-22}$

2. Do you work with special education students? Yes No 3. Do you work onty with special education students? Yes

4. Which of the following screening examinations do you routinely perform for children?

1. Vision

2. Hearing

3. Neurological Health Assessment

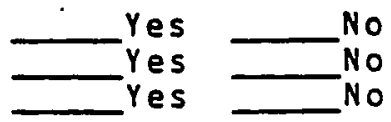


5. How do you share the results of these screenings?

1. Written letters to parents/guardians

2. Verbal reports to parents/guardians

3. Reports to teachers

4. Reports to teams

5. Other (Please explain)

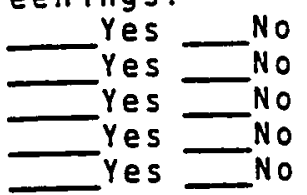

6. Do you routinely screen children for neurological

functioning in relation to learning disabilities?

Yes No

7. If you answered yes to 6 , please name the assessment tool, otherwise go on to 7 .

Quick Neurological Screening Test

Denver-II

other (Piease list by name)

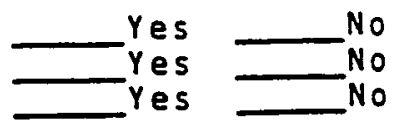

8. Does your school have student study team (SST), or an equivalent method for evaluating individual students who may have been identified by screening tests and/or who are having difficulty in learning? Yes No

9. Are you as the school nurse a member of this team? Yes No

10. Are you asked to do an individual neurological assessment of the child for this study team? Yes No

11. Results from your neurological screening, are used could be used, by the school nurse for student assessment, in which of the following ways?

1. For assessment by the the student study team Yes No

2. For referral to a neurologist

3. To establish need for more extensivelin-depth neurological testing Yes

4. To assist the classroom teacher in meeting $\overline{n e e d s}$

$$
\text { of the student }
$$$$
\text { Yes }
$$
are

12. Results of your neurological screening, shared, could be shared, in which

of the following ways?

1. Written report to parents/guardians

2. Verbal report to parents/guardians

3. Written report to teachers

4. Informal conference with teacher

5. Written report to psychologist

6. Written into I.E.P. goals/objectives

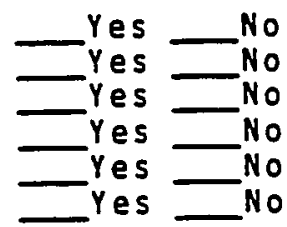


Enclosed are a few of the items from the Quick Neurological screening Test (QNST). Permission has been granted by the authors for the use of these QNST items. They are located on the back of the permission form. The QNST is a neurological screening test which can indicate neurological deficits in children between the ages of 5 and 15 years of age. These neurological deficits have been correlated to specific learning problems of children. Will you please read and evaluate this test and answer the following questions. If you have already provided information regarding the QNST on the previous page, please answer only those questions requesting new information.

1. Have you been taught how to use this test? Yes No

2. Have you ever used this screening test in your practice? Yes No

3. Under what circumstances have you used this test?

1. When requested by school psychologist?

2. When requested by a teacher?

3. When requested by a parent?

4. Self initiated?

5. Other? (Please Describe)

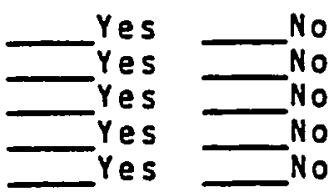

4. If you have used this tool, how frequentiy do you use it?

More than $1-2$ times a month
$=\quad 1-2$ times a month
$-1-2$ times every 3 months
$\square-2$ times every 6 months
$\square \quad 1-2$ times a year

5. If you have not used this test, based on your reading of the enclosed material, do you:

1. Want to know more about it?

2. Do you think you can use it in your population?

3. Does it measure neurological functioning as well as the method you are presentiy using?

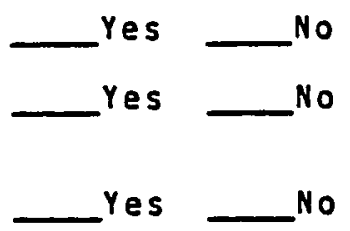

6. I welcome any information that you think is relevant to this topic. 
APPENDIX C

Permission Letter A 
College of Applied Sclences and Arts - Sehool of Nursing - Greduate Program

One Wasningron Square - San Jose. Calitorma $95192.0057 \cdot 408 / 924.1321$

718 Las Trampas Rd. Lafayette, CA 94520 January 23,1995

Dear Dr. Spalding:

In our recent telephone conversation, you, as author of the QNST, gave me your approval to use this test as a part of my masters thesis at San Jose State University. I have decided on my research questions since I talked to you. They are: (1) What neurological assessments are school nurses currently using to screen neurologic function in the school age population? (2) What are the opinions of school nurses regarding the Quick Neurological screening Test and how might it be used in their practice?

I would like to enclose a portion of the QNST Booklet, pages $9-22$, which are the 15 subtests you have designed. My advisor recommended that I include it, in the event that the nurses being surveyed, had not been acquainted with your test. This would allow the data collection to be relevant to the second research question.

At this time, I am formally requesting your permission to copy this segment of your booklet to enclose with the school Nurse Questionnaire. I understand that you can give this permission for yourself and on behalf of your co-authors.

Thank you in advance for your assistance. I am looking forward to meeting with you to discuss my research plans and to learn more about the development of this valuable screening tool. Your dated signature below provides the necessary permission.

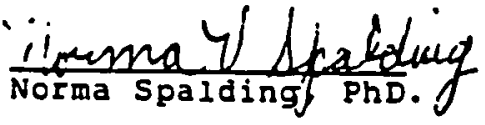

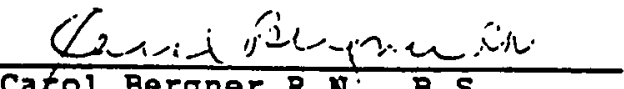

$$
\begin{aligned}
& \text { Special Education School Nurse } \\
& \text { Candidate for the M.S. degree } \\
& \text { School of Nursing } \\
& \text { San Jose State University } \\
& \frac{1 / 27 / 45}{\text { Date }}
\end{aligned}
$$




\section{APPENDIX D}

Permission Letter B 
718 Las Trampas Rd Lafayette, CA 94549

(510)283-0369

March 2, 1995

Trish Bascom

CSNO, President Bay Coast Section

300 Moncada Way

San Francisco, CA 94127

Dear Ms. Bascom:

As per my conversation with Marilyn Radosevic at the CSNO conference in February, I want to thank you, as the new Bay Coast Section President, for your support and permission for me to access cSNo mailing labels. As you know, I am preparing a research study for a masters degree in nursing at San Jose State University.

The topic of my planned research is: A Pilot Study Describing Neurologic Assessment Tools Used By School Nurses To Determine At-Risk Learners In The Grade School Population. I plan to mail a survey questionnaire to each of the nurses included on the mailing list. I will send you a copy of the consent letter and the survey questionnaire to be used, prior to group distribution.

In order to simplify the process of obtaining formal permission for this request, your dated signature below provides the necessary permission. Thank you in advance for your assistance.

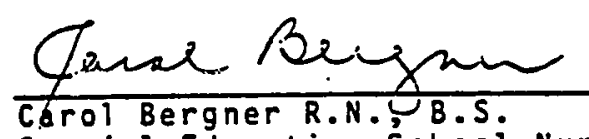
Special Education School Nurse Candidate for the M.S. degree School of Nursing San Jose State University

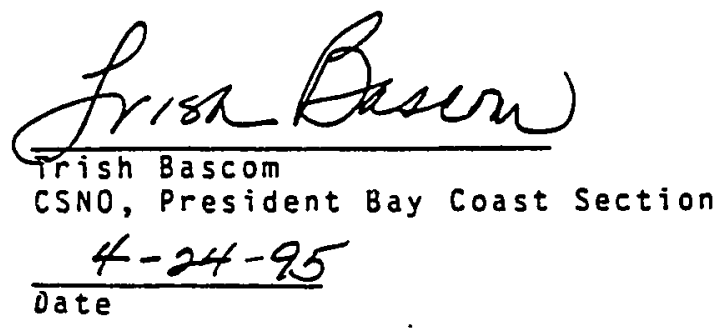


APPENDIX E

Human Subjects Application 
TO:

Carol Bergner

718 Las Trampas Rd.

Lafayette, CA 94549

FROM :

Serena $\boldsymbol{W}$. Stanford AAVP, Graduate studies \& Reseafoh

DATE :

April 24, 1995

The Human Subjects-Institutional Review Board has approved your request to use human subjects in the study entitled:

"Pilot Study Describing Neurologic Assessment Tools Used to Determine At-Risk Learners in the Grade School population"

This approval is contingent upon the subjects participating in your research project being approriately protected from risk. This includes the protection of the anonymity of the subjects' identity when they participate in your research project, and with regard to any and all data that may be collected from the subjects. The Board's approval includes continued monitoring of your research by the Board to assure that the subjects are being adequately and properly protected from such risks. If at any time a subject becomes injured or complains of injury, you must notify Dr. Serena Stanford immediately. Injury includes but is not Iimited to bodily harm, psychological trauma and release of potentially damaging personal information.

Please also be advised that each subject needs to be fully informed and aware that their pariticpation in your research project is voluntary, and that he or she may withdraw from the project at any time. Further, a subject's participation, refusal to participate, or withdrawal, will not affect any services the subject is receiving or will receive at the institution in which the research is being conducted.

If you have any questions, please contact me at (408) 924-2480. 


\section{APPENDIX F}

Narrative Responses on the Use of QNST 
Question number 6 in the QNST section of the survey questionnaire are given below. Results are shown in a pie graph in a pie graph in Figure 1.

1. "This has reminded me of a useful screening tool that I had forgotten about. I would like to relearn how to use it and use it in the future".

2. "It would be nice to have the time to do something like this".

3. "Not used in our district by the nurses at this time. The psychologists do neurological screening".

4. "Unusual for me to do neuro screening at this age (high school)...".

5. "Never, our district sends out students" Will be a PNP this summer and will use it my setting".

6. "There is not enough time to do assessments like this on students who might benefit from them".

7. "I think some of the subtests may overlap with some of the tests that our school psychologist perform i.e. visual discrimination. Realistically, I don't think I would have time to do this on every child referred for special education...".

8. "I have a nurse -- student ratio of 1:4600. Testing more than 1-2 children per year is not practical especially in light of the testing normally conducted by, teacher, \& speech and language teacher...".

9. "I feel other educational disciplines (psychologist, speech, program specialists, teachers) obtain most of this information. As a school nurse, I personally would not be comfortable using/performing this test". 
10. "I need a review and update".

11. "In our district the psychologists often give this test".

12. "Due to reduction of school nurse staff (at present we have 2 full time school nurses for a total student population of ) neurological assessment has had to be relegated to a low priority. I have found the QNST to be valid and helpful, especially in pinpointing specific areas of student weakness and the possible need for more professional testing. However, its length and time in administration, precludes its routine use".

13. "Would use the QNST more often if case load allowed (five schools/3500 students)

14. "I don't believe I'll have time to use the assessment. I'm already committed to a full schedule of screenings, teaching, meetings, \& Individual Education Plans (I.E.Ps)

15. "Used it when I worked with younger students".

16. "I found the QNST quick and easy to give. (It takes a little room. I would have appreciated a workshop on how to give it - it was handed to $\mathrm{me}^{n}$.

17. "I work 3 days a week for 8 schools... Also, it is my experience that we never get helpful information or treatment by referring a child to a dostor for suspected neurological problems. So in order for the test to be useful it should include suggestions for remediation that could be done at school or home and not require a medical referral". 
18. "I don't believe our scope of practice is relevant to this questionnaire".

19. "Our school psychologists do most testing but I would like to know more about it and try it. It looks like a good test but would take a lot of time".

20. The students that I served for 4 years were moderately to profoundly disabled - neurologically, developmentally, physically. Standardized testing could generally not be done due to these limitations".

21. "I haven't used this test I several years - districts have cut back nursing services...".

22. "I would find it difficult to have the time to do such an assessment, although I think it could be a valuable tool".

23. "When I had one school I did use this test but found usually the information could be obtained from other tests, other team members were doing. Also, if a neurological was done by a neurologist there was never any treatment available, just another diagnosis of neurological deficits or learning disabilities which had no medical remediation or treatment".

24. Our student and school numbers were so large (average 4-5 schools/nurse; 2500 students/nurse) that developmental screening such as QNST wasn't feasible for even a few children".

25. "I don't use this test because its very time consuming; not sure of my proficiency; not sure results are worthy of referral".

26. "Work in high school age group, not relevant". 
27. "Would love to have updated inservice on it".

28. “QNST is okay but don't think it's appropriate for all students referred to a Student Study Team (SST). Also, the screening device is time consuming when school nurses times are being cut. So, if student doesn't pass, what happens if the child doesn't qualify after testing is done? For general information, QNST is helpful. Sometimes in young children the skills not mastered are due to immaturity".

29. "Possibly a good tool to use for further referral to a neurologist".

30. "Nurse/student ratio 1:7500, 11 schools".

31. "I am not sure of the psychologists vs. nurse's realm in my district yet so I have to learn more about that".

32. "Caseload is such that we depend on the psychologists and resource specialists testing. If we tell parent a neuro exam is indicated, is the school responsible for the cost?".

33. "School nurses can be very effective in identifying certain neurological phenomena that adversely effect learning. More importantly interpretation of data and appropriate program modification for students should be a key role for the nurse. All too frequentiy Student Study Team members recommend referral to a neurologist when there is no evidence of medically reversible condition. School nurses, well educated, can make a significant impact on cost or care 
containment and program modification for students. Too bad our community is unwilling to consider these facts".

34. "School psychologists use this test, l'm quite sure. With decrease in number of school nurses there will be less time to do auxiliary testing done. Nurses may opt to use this. I did find the Pediatric Evaluation of Educational Readiness (PEER) helpful to teacher, Student Study Team (SSȚ), physician, and parent". 35. "I would interested in more information about this test, e.g. what skill level is expected at various ages and what are the implications of testing". 36. "Work half time at 5 schools. The district gave up all other services when it reduced position to half time".

37. "The test took a while to complete and with 4000 student caseload there is no time for administering test".

38. "I frequently use parts of the QNST - i.e. tandem walk, finger and nose, stand on one leg - to collect data for making referrals for further evaluation. I feel that the complete test and scoring are not always necessary". 